\title{
By the people, for the people The Oregon State University Libraries annual In-Service Day
}

O n September 10, 2008, the Oregon State University (OSU) Libraries shut its doors . . . for the annual In-Service Day event. Eighty employees from all three OSU libraries gathered at the Valley Library on the OSU main campus. Karyle Butcher, university librarian, strongly supports this annual event planned by library staff for library staff and states that "the goal is to learn, to have fun and to develop better relationships and understanding of the departments and units with the OSU Libraries. My belief is that in doing so, we all work better and have a shared view of what OSU Libraries is about." ${ }^{1} \mathrm{En}-$ thusiastic and positive feedback in recent

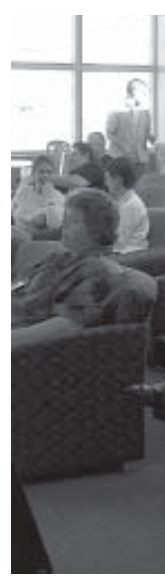

More than 80 Oregon State University Libraries staff members await the start of the 2008 In-Service Day. Photograph by Philip Vue. years indicates that the In-Service Day has captured renewed staff attention and interest. The move to a conference-style format fundamentally changed staff perception of and engagement with this annual event.

\section{An in-service history}

OSU Libraries began holding In-Service Day in 2003. For the first In-Service Day, the university librarian was the morning keynote speaker followed by afternoon breakout sessions. This pattern of having a morning speaker and group activities in the afternoon continued for several years; often In-Service
Day centered on a single topic. After the keynote speech, library staff broke up into small groups to discuss various aspects of the topic and reconvened at the end of the day to share their findings with the larger group. While the importance of discussing issues facing the OSU Libraries community seemed like a good activity for the day, in reality, these activities often fell flat due to the diverse personalities, responsibilities, and roles of library

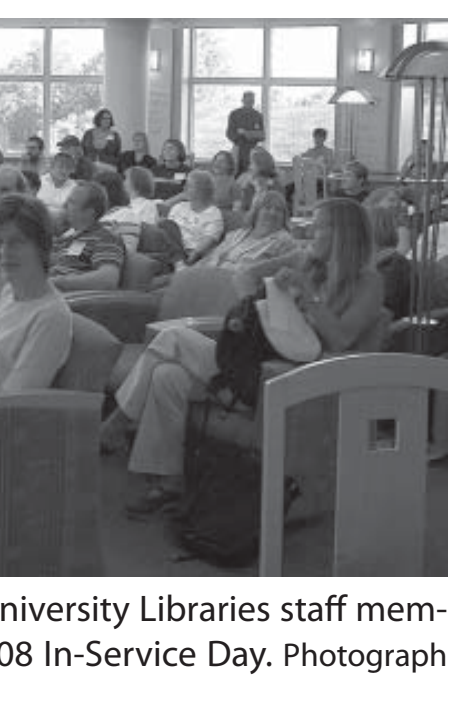
employees.

Feedback indicated employee dissatisfaction with the event. Less than a third $(n=11-25)$ of library staff completed evaluations, and those who did were quite critical of the event. The most common complaints focused on logistics and content. In-Service Day planners did incorporate feedback by moving the day's activities into more comfortable library spaces, including hands-on activities and incorporating library staff presentations. Staff reacted positively to these changes; however most staff were still only passively involved in

\footnotetext{
Uta Hussong-Christian is physical and mathematical sciences librarian, e-mail: uta.hussong@oregonstate. edu, Sue Kunda is digital production librarian, e-mail: sue.kunda@oregonstate.edu, Hannah Gascho Rempel is graduate student services coordinator, e-mail: hannah. rempel@oregonstate.edu, at Oregon State University ๑) 2009 Uta Hussong-Christian, Sue Kunda, Hannah Gascho Rempel
} 
the day's activities and buy-in remained low.

The 2007, In-Service Day planning committee consisted of many new employees who did not feel tied to past In-Service Day models and were willing to explore alternative options. The committee came up with the idea of a conference-style format that might appeal to many different interests, and, at the same time, increase interaction and community building among employees.

A theme was developed-"Building Community; Exploring New Horizons"and corresponding conference tracks were brainstormed. Twenty-four half-hour sessions were scheduled, and all staff members were encouraged to create and lead sessions related to the track topics. OSU Libraries staff gamely accepted the challenge, creating sessions, including book-binding, Web 2.0 tools, and a field trip to the library's server room. Because so many staff were involved in presenting, there was more buy-in from the entire staff, and people arrived eager to engage with their colleagues and to learn new things. This shift in format broke new ground for the OSU Libraries In-Service Day and provided a template for future In-Service Day events.

\section{The many details}

Although each year's In-Service Day is unique, planning for the conference-style event is developing a regular routine. Library mangers start the process with a call for committee members several months before the In-Service Day; members represent various departments and include both professional and nonprofessional staff. Library managers also call the first meeting where a chair is selected, a theme is developed, and a regular meeting time is established.

The planning committee selects the InService Day date, taking care not to conflict with other library and campus events. Committee members contact potential keynote and luncheon speakers, and solicit OSU Libraries staff and outside persons to present at In-Service Day. Both professional and nonprofessional staff are encouraged to develop presentations. This increases staff engagement and ensures relevant sessions are provided for all employees.

Proposals are reviewed and assigned to the appropriate conference track. A schedule is developed and a poster-sized schedule copy is printed for display on In-Service Day. The committee makes online registration and session selection available via survey software. This information is imported into a spreadsheet and is used to create individual schedules for each attendee. To maintain the conference-style feel, name badges are created and a registration table is set up.

The 2008 committee chair greatly improved communication and coordination between committee members when she emphasized use of the In-Service Day wiki. This Web-based tool gives each committee member access to all planning documentation without the restrictions sometimes encountered when using a shared network space. The wiki also provides a historical record for future In-Service Day planning committees.

Finally, the big day arrives. The OSU Libraries In-Service Day is run much like any other conference; the day begins with registration, coffee and other refreshments, and mingling with colleagues rarely seen during normal working hours. Dressing down is encouraged, allowing everyone to feel more relaxed. The university librarian and committee chair make opening remarks, the keynote speaker is introduced, and the day is officially underway.

When the keynote speaker is finished, attendees move to their first session. Surprisingly, there is little work to do during the actual In-Service Day. Because most presenters are OSU Libraries staff, and are often accustomed to speaking in front of groups, there is no need for committee members to facilitate those presentations. Outside presenters, however, are accompanied by committee members who briefly introduce the speaker and troubleshoot any problems that may arise.

After the morning sessions, the staff reconvenes for a catered meal, more informal mixing, and a lunchtime speaker. Afternoon sessions essentially follow the same format as morning sessions, and the staff gathers once 
more at the end of the day. The university librarian provides brief closing remarks and In-Service Day ends. The next morning a short, previously prepared evaluation is delivered to all attendees via online survey software.

Several weeks later, the In-Service Day Committee meets one last time to discuss feedback gathered from the evaluations and makes recommendations for the next year's In-Service Day. This information is posted to the wiki and passed on to library administration in a written report.

\section{The people respond}

In-Service Day feedback is invaluable for planning the next year's event. It helps establish and maintain expectations year after year, provides information and ideas about possible changes in event structure or programming, and gives new employees on the planning committee a better understanding of what InService Day is all about.

In light of the format changes implemented the previous year, review of the 2007 feedback was very helpful for the 2008 In-Service Committee. The number of responses in 2007 was not only significantly higher $(n=53)$ than in previous years, but feedback was overwhelmingly positive. Comments indicated that attendees enjoyed the new conference-style event for several reasons: sessions were short, there was a great variety of sessions from which to choose, staff were able to spend a considerable amount of time networking, and staff had an opportunity to explore unfamiliar spaces inside the library.

Not all changes were viewed positively, however. Some staff felt rushed with the short sessions and the limited time allotted for moving from one session to the next. In addition, several respondents commented they would have liked to participate in outdoor activities.

The 2008 planning committee carefully considered this feedback in developing the schedule for the 2008 In-Service Day. Longer sessions were scheduled for the morning (which allowed for more activities as well as tours outside the library), the time between sessions was lengthened, and more breaks were incorporated (which allowed for additional networking and time to visit the poster sessions).

Feedback from the 2008 In-Service Day was, once again, overwhelmingly positive. Staff were still enthusiastic about the conference-style format, enjoyed the variety of sessions offered, and appreciated the longer between-session times and breaks. Just over half of all respondents ( $\mathrm{n}=59)$ saw networking opportunities as a very valuable outcome of their day. This informal mode of communication remains highly important despite the plethora of tech-based communication options available to each staff member.

Feedback was split almost evenly between faculty and staff, perhaps indicating that both groups felt equally engaged and invested in the day's events. Respondents from both groups offered suggestions for future InService Days, which will be extremely valuable for future planning committees.

\section{An unfinished work}

The experiences of the OSU Libraries InService Day planning committee highlight several issues to consider when planning a conference-style In-Service event. First, start the planning process early. Choose the next year's theme shortly after the annual In-Service Day so committee members have ample time to find a suitable keynote speaker and to allow library staff plenty of time to create and design relevant programs.

Second, consider using Web-based software to maintain In-Service Day-related documents and enhance communication among committee members. Now that we have created a wiki and online evaluation form, it will be a simple matter to update those in future years.

Third, tap into the experience and networking power of library administrators. The OSU Libraries planning committee includes an administrative representative who provides a historical context for planners, as well as an overall knowledge of library and campus protocols. This representative can also act as a liaison, keeping administrative staff informed

(continues on page 403) 
Gen X, and Gen Y) actively working together, experts contend that one element critical to success as a society is these different age groups' ability to effectively communicate. In addition to summarizing the generations' characteristics, the author provides tips for communicating with each group. Access: http://www.thebusinessledger.com/Home /Archives/CommentaryViewpoints/tabid/86 /newsid415/478/Communication-key-to -cross-generational-relationships/Default.aspx.

- Tips to Improve Interaction Among the Generations: Traditionalists, Boomers, X'ers and Nexters. Values can collide when members of generations learn and work together. This article provides a better understanding of today's generations-Traditionalists, Baby Boomers, Generation Xers, and Generation $\mathrm{Y}$ - and offers tips for successful communication among the groups. Access: http://honolulu.hawaii.edu/intranet /committees/FacDevCom/guidebk/teachtip /intergencomm.htm.

- Today's Generations Face New Com-

("By the people ..." cont. from page 399)

of the committee's progress and relaying any information back to the committee. Additionally, library administrators can use their network of contacts to help locate the keynote and any other speakers.

Fourth, encourage and celebrate programs developed by library staff. In 2007 and 2008, the planning committee announced the conference theme and associated tracks to employees but made no stipulations about possible programs. Staff educated, entertained, and amazed everyone with their interpretations of the days' topics. These presentations allow staff to develop, use, and highlight their creativity as well as hone their public-speaking skills. Nearly one-third of the OSU Libraries staff now actively participates in various aspects of the In-Service Day.

Finally, the planning process should allow each year's planning committee to add their unique touch to this annual event. While we have a successful template for developing an munication Gaps-USATODAY.com, Denise Kersten. The author notes that she has come across several career books that address the widening generation gap in the workplace, due to four distinct generations working together. In this article, Kersten provides a comparison of communication styles of Traditionalists, Baby Boomers, Generation X'ers, and Millennials. Access: http://www. usatoday.com/money/jobcenter/workplace /communication/2002-11-15-communication -gap_x.htm.

- Understanding and Appreciating the Communication Styles of the Millennial Generation, Jenna Reith. According to Reith, generational culture is one very important aspect in developing personality and communication. In this article, the author highlights important influences on the communication styles of Millennials, which include diversity, their parents, educational trends and challenges, psychological issues, technology, and popular culture. Access: http://counselingoutfitters.com/vistas /vistas05/Vistas05.art70.pdf. z

In-Service Day, it is not so rigid that it constrains either the planning committee or the program presenters. In 2008, several groups asked to provide poster sessions, something that had not been done before. The committee agreed, the sessions were a resounding hit, and they will likely be incorporated into future In-Service Day events. This willingness to seek and adapt to new ideas will keep the event fresh and exciting.

OSU Libraries believes its In-Service Day can serve as a model for other libraries seeking innovative ways to educate, train, engage, and connect with staff across departments and branches. While it may not be feasible for other libraries to develop a day-long event, some significant time dedicated to an In-Service Day event of this nature is well worth the investment.

\section{Note}

1. Karyle Butcher, e-mail message to OSU Libraries staff, October 29, 2008. z 